\title{
Prognostic factors of post-traumatic stress disorder risk in patients with surgical treatment of hip acetabular fracture. Original study
}

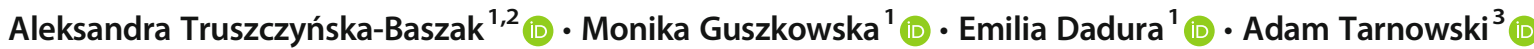

Accepted: 11 February 2021 / Published online: 23 February 2021

(C) The Author(s) 2021

\begin{abstract}
The aim of the study was to assess the risk of developing post-traumatic stress disorder in patients after hip acetabular fracture surgery. The study involved 42 patients fulfilling inclusion criteria. Physical ability levels of the patients were determined with the Harris Hip Score, and modified Merle d'Aubigné scale. High risk of post-traumatic stress disorder was assessed with the PTSD-C questionnaire. Patients had in PTSD-C questionnaire 42.86 $\pm 28,10$ points. In Harris Hip Score 63.64 \pm 16.06 , in Merle scale $11.10 \pm 2.82$, that was poor results in both scales. Positive correlation with age reached the level of tendency $(\rho=0.294 ; p=$ 0.059). Patients at risk of PTSD were in worse functional state measured by HHS $(\mathrm{U}=136.0 ; p=0.034)$ and Merle scale $(\mathrm{U}=$ $132.0 ; p=0.026)$ and they were older $(\mathrm{U}=147.5 ; p=0.068)$. The groups differed significantly in gender ratio $\left(\chi^{2}=4.01 ; p=\right.$ 0.045). Women (8/10) were more often than men (14/32) at risk of PTSD. Patients after surgical fixation of the acetabulum experience significant functional disability. Increased level of disability after fracture and surgery, older age and female sex make patients vulnerable to PTSD. It is advisable to make medical staff who treat accident victims aware towards aspects which may be related to disorders of the patients' psychological health.
\end{abstract}

Keywords Acetabular fractures of the pelvis $\cdot$ Functional state $\cdot$ Post-traumatic stress disorder

\section{Introduction}

Epidemiologic studies show that pelvic injuries amount to $3 \%$ of all skeleton injuries. Among pelvic injuries, $10 \%$ are acetabular fractures. Death incidents related to such injuries amount to $10-16 \%$ for closed fractures and $45 \%$ for open fractures (Dente et al., 2005; Grotz et al., 2005). While acetabular fractures are only a small proportion of all injuries, they result in considerable social and economic costs (hospitalization, sick leaves, physiotherapy benefits) as they usually involve young men at working age (Aprato et al., 2016). Research has shown that the proportion of subjects suffering from chronic pain syndrome resulting from acetabular injuries

Aleksandra Truszczyńska-Baszak aleksandra.rapala@wp.pl

1 Faculty of Rehabilitation, Józef Piłsudski University of Physical Education in Warsaw, Marymoncka 34, 00-968 Warsaw, Poland

2 Professor A. Gruca Independent Public Research Hospital, Otwock Department of Orthopaedic Surgery, Konarskiego 13, 05-400 Otwock, Poland

3 Department of Psychology, Nicolaus Copernicus University, Toruń, Poland may amount to $45 \%$, therefore leading to considerable lowering of patients' quality of life and to limiting their sport activity (Giannoudis et al., 2009).

The type of fracture depends both on the position of the limb during accident, and on the force direction. These injuries are most commonly caused indirectly, during the so called dash-board injuries, when the dash board strikes patient's bent limb, and the limb transfers the magnitude of the strike and injures the acetabulum (Culemannet et al., 2009; Moliere, Dosch, \& Bierry, 2016). Surgical treatment is complicated, surgeries last several hours, involve enlarged surgical access, reducing dislocation, careful setting of numerous fractures and their stable fixation (Figs. 1 and 2).

PTSD after bone fractures (but not pelvis) were evaluated by other researchers. Johnson et al. (2019) concluded that psychological support and counseling should be implemented as part of the standard care to a patient suffering from such a long-term complication like a fracture non-union. Kornfield, Lenze, and Rawson (2017) found that higher levels of depression symptoms at baseline were associated with higher levels of PTSD symptoms 12 weeks after surgery of hip fracture. Muscatelli et al. (2017) found that 33\% of patients suffered from depression and more than 25\% from PTSD after an acute orthopedic injury. They suggested that strategies to address 
Fig. 1 Computer tomography of pelvis (3D reconstruction)

Fig. 2 Post-surgical image of acetabular fracture
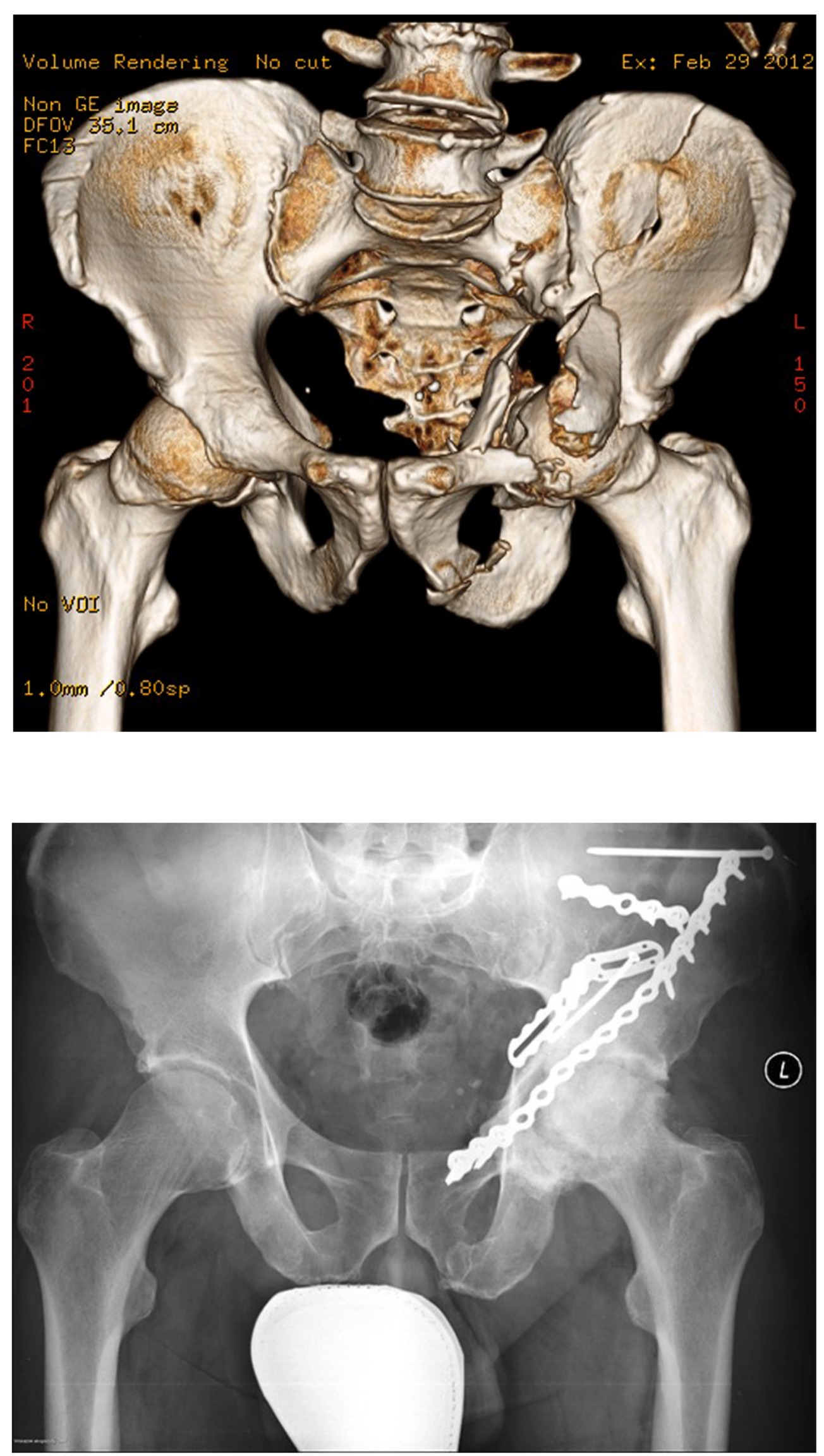
both the mental and physical rehabilitation after an orthopedic injury should be considered to optimize patient recovery. Also according to Aaron, Fadale, Harrington, and Born (2011) there is a need to assess symptoms of PTSD among orthopedic patients and to make referrals for psychiatric services. Patients with greater number of post-traumatic stress risk factors experienced poorer outcomes following orthopedic surgery (Cremeans-Smith et al., 2015). People undergoing hip acetabular fracture surgery are therefore at risk of PTSD due to trauma caused by the injury itself and major surgery. This risk can be expected to be greater in patients who have suffered a hip fracture in a traffic accident. A traffic accident alone can cause PTSD, as direct exposure to trauma is in criterion (APA, 2013).

Road traffic accidents are one of the causes of acetabular fractures. The trauma related to a road traffic accident and the complicated surgical treatment put patients at high risk of developing post-traumatic stress disorder (PTSD) (Zawadzki, Strelau, Bieniek, Sobolewski, \& Oniszczenko, 2002). In 2013, the American Psychiatric Association revised the PTSD diagnostic criteria in the fifth edition of its Diagnostic and Statistical Manual of Mental Disorders (DSM-5). PTSD is included in a new category in DSM-5, Trauma- and StressorRelated Disorders. All of the conditions included in this classification require exposure to a traumatic or stressful event as a diagnostic criterion (APA, 2013). A road traffic accident itself is a strong stressor. Accompanying pain and trauma increase the risk of PTSD.

It seems that with the increasing number of vehicles on roads and rising numbers of victims of road traffic due to motorcycle (increase of $33.1 \%$ in the last 10 years) and bicycle accidents (increase of $54 \%$ in the last 10 years), health care professionals (non-psychologists) will be facing the challenge of PTSD more often (https://www.krbrd.gov.pl/pl/test.html access date 16.10.2020). This is why it is essential for them to be able to recognize PTSD symptoms and predict its risk, to assess their impact on the patient and to refer the patient early to a competent specialist. Research's' results indicate that PTSD and pain does frequently occur among patients after motor vehicle accidents (Jenewein, Wittmann, Moergeli, Creutzig, \& Schnyder, 2009), or surgery (Page, Kleiman, Asmundson, \& Katz, 2009). Studies showed that approximately $11-13 \%$ accident victims develop PTSD symptoms (Harvey \& Bryant, 1998). According to other sources, as many as $50 \%$ of the injured suffer from the syndrome (Fekadu, Mekonen, Belete, Belete, \& Yohannes, 2019). Psychological and social functioning disorders may result in lowered motor abilities in patients after pelvic injuries.

It can be assumed that the severity of PTSD symptoms in this group of patients will depend on similar factors as those disclosed in studies of other clinical groups. The first factor is being female. Women are affected by PTSD at twice the rate of men (APA, 2013). Gender influenced the prevalence of
PTSD among victims of road traffic accidents, with females more likely to experience PTSD (Iteke, Bakare, Agomoh, Uwakwe, \& Onwukwe, 2011).

The severity of PTSD symptoms varies over time, and it can be assumed that the time elapsed since the injury may be another factor. Recent studies show heterogeneity in the development of PTSD-symptoms and fluctuation of PTSDsymptoms over time (e.g. Berntsen et al., 2012). Research from Australia showed that initially after the accident $23.6 \%$ of participants had PTSD, $11.5 \%$ at 3 months, $9.7 \%$ at 6 months and $7.0 \%$ at 12 months. There was decline in symptoms with time but some individuals were symptomatic later despite being asymptomatic earlier (Jeavons \& Greenwood, 2000).

The literature showed a general, though not consistent, relation between PTSD and obesity. This relationship is usually thought of as unidirectional - PTSD has frequently been found to have an effect on the development of obesity (Johannessen \& Berntsen, 2013; Aaseth, Roer, Lien, \& Bjørklund, 2019). This comorbidity has also been found when comparing a PTSD versus a non-PTSD population in relation to overweight and obesity (Alvarez, Pavao, Baumrind, \& Kimerling, 2007; Dedert et al., 2010). However, the results of correlation did not determine the direction of this relationship.

Suffering from severe pain following a trauma was associated with risk for PTSD due to the neurobiological proximity and similarity of processing mechanisms of physical and psychological pain stimulation and extremely negative emotions (Walter, Leissner, Jerg-Bretzke, Hrabal, \& Traue, 2010).

The last but probably the most important factor is the functional state of the patient after the injury. Pain evidenced strong associations with reduced functioning across both physical and psychosocial domains (Clapp, Masci, Bennett, $\&$ Beck, 2010). Compared to patients without pain, patients with pain were more likely to have functional limitations in daily activities and did not return to work (Herrera-Escobar et al., 2018).

There is a growing body of research revealing relationships between injury, pain and psychological trauma with important implications for the prevention and management of post-traumatic reactions. Recent work suggested that stress and pain interact through the effects of injury and the distress in response to perceived threat (Kenardy \& Dunne, 2011). However, in the available literature, no study was found regarding the risk of PTSD in patients who suffered a hip acetabular fracture as a result of a traffic accident and the factors that predict the severity of PTSD symptoms. In the case of mental disorders, however, we must take into account the cultural context. There are no studies devoted to this issue carried out in Poland. Knowing the prognostic factors of PTSD risk in Polish patients with surgical treatment of hip acetabular fracture will allow us to develop effective intervention and prevention programs for them. 
To sum up it can be assumed that the severity of PTSD symptoms in this group of patients will depend on similar factors as those disclosed in studies of other clinical groups: being female, time from injury, obesity, severity of pain, and functional disability.

The aim of the study was to assess the risk of developing post-traumatic stress disorder in patients who had surgical treatment of hip acetabular fracture and to determine the predictors of the severity of PTSD symptoms that plays important role at different levels of patients' care: surgeons and other medical doctors, psychologists, physiotherapist, nurses and patients' families and their communities.

\section{Material and Methods}

Participants. Prior to the study, we have obtained the consent of the of the Senate Commission of Ethics of Scientific Research (SKE 01-21/2014), from the director of the Hospital, from the senior registrar of the Pelvic Pathologies Ward, and written declarations from every patient in which they expressed their informed consent to participate in the study. In the years 2014-2017 we have examined a total of 55 patients who had surgical treatment for acetabular fracture. Data were collected data by author E.D. with help of orthopedic surgeon from pelvic surgery ward. Participants did not receive any financial compensation for participation in the study.

The criteria for subject inclusion were the following: written informed consent, surgically treated acetabular fracture, time post-surgery: minimum of 2 months, full cognitive ability, full medical records. The criteria of subject exclusion were: cranial and cerebral injuries, visual system disorders, neurological disorders, ear and sinus infections, spinal pain, other injuries to the lower extremities, chronic diseases (cancer, Parkinson's disease, epilepsy, diabetes, neuro-muscular disorders, unsupervised coronary thrombosis), taking psychoactive substances, deep vein thrombosis to lower extremities (Giannoudis et al., 2009; Lang et al., 2016).

After application of the inclusion and exclusion criteria, the study population had 42 subjects ( 32 men and 10 women). All participants were Polish citizens. The studied population sample represent the population of interest as we evaluated all prospective patients fulfilling the inclusion criteria. Orthopaedic department were patients had hip acetabular reconstruction is the only one in Poland that makes that procedures continuously for many years now. The age of the subjects ranged from 20 to 72 years, mean $44.60 \pm 14.31$. The most common cause of the injuries in the study population were road traffic accidents ( 29 subjects; in 7 subjects it was a fall from height and in 6 subjects - other causes). The mean time after surgery and after examination was mean $39.3 \pm$ 49.05 months.
Measure. To determine the level of symptoms that may inform of post-traumatic stress disorder, we used the PTSDC (C - clinical version) questionnaire (Zawadzki et al., 2002). This tool was chosen by experienced psychologist AT because of its simplicity and because a non-psychologist (here, an experienced physiotherapist ED) was able to administer it. The tool did not explicitly diagnose the disorder. To diagnose the disorder, the patient would have to undergo a multifaceted examination by a qualified specialist - a psychologist or a psychiatrist. Still, the tool let us identify some symptoms that allowed for the determination of risk of the disorder that could possibly be related to the functional state of the patients.

The questionnaire contained 40 statements on various reactions to the traumatic event. The patients were asked to mark their given reactions in the past month on the Likert scale $(0=$ never, $1=$ rarely, $2=$ often, $3=$ always $)$. The higher the score (a maximum of 120 points), the more likely it was that the patient was having symptoms suggesting post-traumatic disorder. The critical value was set by the authors of the questionnaire at 38 points. Subjects scoring more than 38 may experience PTSD (Zawadzki et al., 2002). The analysis of the results was conducted in cooperation with two professors of psychology (MG and AT) who had had many years of professional experience. The patients completed the questionnaire on their own, having received thorough instructions by the person conducting the examination. Scale reliability in a current study has been primarily estimated as satisfying (Cronbach's $\alpha=.955$ ).

We determined patients' functional state on the basis of Harris Hip Score (HPP). This is an orthopedic tool which assesses functional state of patients after hip interventions. Harris hip score showed high validity and reliability (Soderman \& Malchau, 2001).The tool assesses the following aspects: pain in the operated limb, hip movement range (registered with hand held goniometer), gait (limp, the distance a patient is able to walk, using mobility aids), other activities (walking the stairs, putting on shoes, and sitting, using public transport). Patients scored points for each analyzed element. The maximum number of points was 100 . The score reflected the level of patient's functional state (a greater number of points meant that the patient had better ability). Then, we compared the results to the norms (Kirmit et al., 2005).

A Modified Merle d'Aubigné scale (Merle scale) was also used to determine pain during activity. It assesses the level of pain (from 2 - severe pain to 6 - none pain); walking ability (from 1 - unable to walk to 6 - normal walking), range of motion (1point - $0-30 \%, 6$ points $-211-250 \%$ ). The maximum score of 18 points is an excellent clinical result, 15-17 good result, 13-14 fair, and below 13 poor (Merle D'Aubigne \& Postel, 2009). The Modified Merle d'Aubigné scale was proved to have high significance and reliability: high interevaluators reliability for the items: prefix $(p<0001 ; \alpha=$ 
$0.961)$, pain $(p<.001 ; \alpha=.892)$, gait $(p<.001 ; \alpha=.898)$, mobility $(p<.001 ; \alpha=.810)$ and total score $(p<.001$; $\alpha=$.917) (Ugino et al., 2012).

The patients did not have any other interventions before our examinations. HHS and Merle scales were performed by experienced physiotherapist (ED). All measurements were performed in quite, separate room in the morning.

\section{Statistical Analysis}

We used SPPS Statistics v. 25 programme to process the obtained results. We used the Kolmogorow-Smirnow test to assess normal distribution of variables. Because some of the analyzed variables did not meet the requirements of normal distribution, nonparametric tests were used. To determine the relationships between variables, Spearman $\rho$ correlation coefficients were calculated. Mann-Whitney U test was used to compare groups. The significance of differences in distributions was assessed by $\chi^{2}$ test. A discriminant analysis was performed (ENTER method) to determine the prognostic factors of PTSD in patients. We set statistical significance at $p \leq$ 0.05 .

\section{Results}

The mean number of points patients scored in PTSD-C questionnaire was $42.86 \pm 28.10$ points. The mean patient Harris Hip Score was $63.64 \pm 16.06$, and when compared with normative values of the tool, it meant that patients had poor functional ability. In Merle scale mean was $11.10 \pm 2.82$, which is a poor result.

\section{Relationships between Variables}

The PTSD symptom severity index did not significantly correlate with height and body weight, or the time since injury and surgery. Two significant negative relationships with the indices of functional state were found: the HHS score $(\rho=$ $-0.412 ; p=.007)$ and the Merle scale score $(\rho=-0.327$; $p=.035)$. Positive correlation with age reached the level of tendency $(\rho=0.294 ; p=.059)$.

\section{Comparison Based on PTSD Risk}

Patients $(n=22 ; 52.4 \%)$ who scored above the critical threshold of 38 points had several symptoms that informed of risk of developing PTSD. Other patients $(n=20)$ obtained a score below 38 points, indicating no risk of PTSD. Patients at risk of PTSD were in worse functional state measured by HHS $(\mathrm{U}=136.0 ; p=.034)$ and Merle scale $(\mathrm{U}=132 ; p=.026)$ and they were a bit older $(\mathrm{U}=147.5 ; p=.068)$. The groups did not differ significantly in weight $(\mathrm{U}=185.5 ; p=.385)$, height $(\mathrm{U}=170 ; p=.206)$ and time post injury $(\mathrm{U}=156.0$; $p=.339$ ).

The groups differed significantly in gender ratio $\left(\chi^{2}=4.01\right.$; $p=.045)$. Women $(8 / 10)$ were more often than men $(14 / 32)$ at risk of PTSD. There were no group differences depending on the cause of the injury (road traffic accidents $n=29$ versus others: fall from height $n=7$ and other causes $n=6)\left(\chi^{2}=\right.$ $0.29 ; p=.588)$.

\section{Prognostic Factors of PTSD}

The next step in the analyses was to determine the prognostic factors of PTSD in patients. The predicted variable was belonging to the group of people whose PTSD-C scores exceeded the threshold value of 38 , considered to be the limit of clinically significant symptoms.

A discriminant analysis (with use of ENTER method) was performed, to assess the possibility of predicting the occurrence of a clinically significant level of PTSD, in which Age, Body height, Gender, Bodyside affected, Traffic accident (as the cause of injury), Time from injury, and raw scores from HHS and Merle scales. Body mass was excluded from the analysis due to its strong correlation with gender and height to avoid colinearity. Finally, the canonical discriminant function's eigenvalue was 0.923 , which proves that the selected independent variables were correctly fitted to the model.

Due to the relatively small size of the groups bootstrapping has been implemented. To assess collinearity Eigenvalue computed for canonical discriminant function is 0.923 .

Derived function allows for statistically significant prediction (Wilk's Lambda $=0.520 ; \chi 2=21.582 ; \mathrm{DF}=8 ; p=$ 0.006).

The function values at group means are 0.960 (for low PTSD group) and 0.920 (for clinically significant PTSD). The function allows for $84.6 \%$ correct classifications of PTSD in the sample. The discriminant analysis confirmed,

Table 1 Standardized discriminant canonical function coefficients predicting clinical PTSD level based on the examined independent variables

\begin{tabular}{lc}
\hline Variable & Coefficient \\
\hline Age & .65 \\
Body height & -1.07 \\
Gender* & .32 \\
Body side affected** & .46 \\
Traffic accident*** & -.006 \\
Time period from injury & -.64 \\
HHS & -.03 \\
Merle & -.97
\end{tabular}

$*$ Male $=1$, Female $=2 ; * *$ dominant side $=1$, non-dominant side $=0$; $* * *$ traffic accident $=1$, other $=0$ 
that the risk of clinically significant PTSD symptoms can be effectively predicted on the base of individual factors connected with injury and rehabilitation process (Table 1).

\section{Discussion}

Our results confirmed that patients after surgical treatment of hip acetabular fracture were at risk of PTSD and had poor functional ability. More than half of the patients we surveyed scored above the cut-off level, indicating a risk of PTSD. The mean number of points patients scored in PTSD-C questionnaire was above 42 points that was similar to obtained data with presented in Zawadzki et al. (2002) study PTSD scores of flood victims. We found that patients of the female gender and older age, experiencing greater pain during daily activity and suffering from trauma on the dominant side of the body are more at risk of PTSD. The risk of PTSD was greater in the shorter post-trauma period. Body height also turned out to be an important factor.

The psychological symptoms that can occur as a result of accidents are increasingly being documented as well as efforts being made at early detection and understanding of who is vulnerable to PTSD. The major types of disorder that people suffer include symptoms of PTSD such as flashbacks, nightmares, avoidance, hyperarousal, emotional numbing, and phobic anxieties about travel, depression, grief and changes in driver behavior (Jeavons \& Greenwood, 2000). PTSD is common in patients after injury, including those with orthopedic trauma (Warren et al., 2016; Zatzick et al., 2007). Jiang et al. (2018) examined the incidence rate of overall and specific fractures among patients with clinician-diagnosed PTSD $(n=4114)$. Their findings suggest that PTSD is associated with increased fracture risk. Other authors found that PTSD is common in patients after injury, including those with orthopedic trauma. At 6 months, pain of 5 or greater, poor physical and mental function, depression, and/or not returning to work seem to be predictive of PTSD. Orthopedic surgeons should identify patients and refer them to treatment if they suspect high incidence of post injury PTSD (Warren et al., 2016). Our results confirmed that patients after surgical treatment of hip acetabular fracture were at risk of PTSD. The average level of symptoms is comparable with flood victims investigated by Zawadzki et al. (2002). Also the strength of the relationship between the disability level and PTSD symptoms is comparable with presented by Zawadzki et al. (2002, tab.6.) coefficients of coincidence with objective trauma levels.

Looking for the prognostic factors of PTSD in patients, we found that one of them is pain experienced during activity. Chronic pain and PTSD are known to hold substantial comorbidity following traumatic injury. Norman, Stein, Dimsdale, and Hoyt (2008) found that pain was associated with an increased risk of PTSD. We expected pain to be a predictor of
PTSD because of the neurobiological proximity and similarity of processing mechanisms of physical and psychological pain stimulation and extremely negative emotions. The close relationship and the etiological and behavioral similarities of both disorders have led to the development of joined vulnerability and mutual maintenance models (Walter et al., 2010). Herrera-Escobar et al. (2018) obtained similar results. Compared to patients without pain, patients with pain were more likely to screen positive for PTSD.

Patients at risk of PTSD were in worse functional state measured by HHS and there was a negative correlation between PTSD-C and HHS. The relationship between functional status and PTSD was observed in previous study by HerreraEscobar et al. (2018). The relationship between PTSD and functional state can be bidirectional. Functional limitations, at least in part due to pain, can worsen PTSD. A person with PTSD may be sensitive to pain and prone to perceive their functional abilities as limited.

Our results indicated that women were more often than men at risk of PTSD. Being a woman was a prognostic factor of post-traumatic stress symptoms. This is in line with the results of previous studies (Norman et al., 2008; Zatzick et al., 2002) that female gender was a risk factor for PTSD. It is unclear if this difference is due to gender specific pathways in the underlying mechanisms of PTSD (Pineles, Arditte Hall, \& Rasmusson, 2017) or to gender-relevant differences in rates of experiencing trauma (Cowden Hindash et al., 2019).

Four studies that have prospectively followed up road accident victims for a year in England, USA and Israel found $16.5 \%, 14.3 \%, 14 \%$ and $32 \%$, respectively, met the criteria for PTSD at one year (Jeavons \& Greenwood, 2000). In our study, the cause of the injury did not differentiate the proportion of people with a PTSD-C result above and below the cutoff point, so there was no greater severity of PTSD symptoms in those who suffered a hip fracture as a result of a road traffic accident. The cause of the injury was also not a prognostic factor of PTSD. Our predictions have not been confirmed.

In our study, over half of patients had symptoms which could reveal problems on clinical level and should receive psychological care. However, it has to be clearly stated that the aim of the PTSD-C questionnaire was not to give a psychological diagnosis, but only to take a wider perspective on patients after reconstruction of the hip acetabulum. We used the questionnaire as a screening test to decide if patients had symptoms which may possibly require a psychiatrist's or a psychologist's consultation. It also seems important from other health care professionals' perspective. They could recognize patients' psychological issues at an early stage, but they often lack adequate tools to assess their psychological states. Here, the PTSD-C questionnaire may become a useful screening tool.

It is also essential to monitor such patients in long term perspective. A literature review by Wiseman, Foster, and 
Curtis (2013) showed that PTDS, depression and anxiety that follow traumatic experiences are often poorly identified while treating physical injuries, and this impact accident victims' psychological states. Early screening and diagnostics of mental issues of the patient in the acute phase is not done routinely in such injuries. If the patient is not guaranteed a psychological health specialist care during their acute phase in hospital, as is often the case, then access to such care may be even more restricted in outpatient clinics. Although our study was conducted in one of the most specialist hospitals treating acetabular fractures in Poland, most study population patients came from smaller towns or villages, where access to psychologist's consultation is restricted. This in longer perspective, means that patients do not receive adequate care in this respect.

Mental disorders caused by post-traumatic stress may also impact those areas of patients' health which a physiotherapist takes care of. Symptoms which accompany trauma induced anxiety disorders impact the motor system, as they affect the nervous system - which steers the motors system. A number of symptoms, such as numbness, agitated autonomic nervous system and insomnia may impact the level of physical ability of patients after surgical treatment of acetabular fracture, and therefore lead to decreased quality of life. In our study two significant negative relationships between the level of PTSD and the indices of functional state were found. This relationship is confirmed by the fact that patients at risk of PTSD were in worse functional state measured by HHS and Merle scale a negative value of the correlation coefficient defined the type of relationship between studied parameters, yet it did not determine its direction. It seems difficult, therefore, to explicitly define which of the elements had a decisive role: whether it was that better functional states resulted in lowered stress symptoms, or lower levels of post-traumatic stress made it easier for patients to conduct activities of daily living and have a better social life.

There is general agreement that the way a patients is treated after the serious injury has a major impact on the development of PTSD. There is some empirical literature rehabilitation intervention is more important in preventing PTSD symptoms. $\mathrm{Ni}$ et al. (2013) evaluated the effectiveness of a rehabilitation on physical dysfunction and PTSD in fracture victims 50 months after the Sichuan earthquake and found that symptoms were significantly reduced by the rehabilitation intervention. They concluded that medical intervention strategies should include rehabilitation in order to assist survivors in dealing with both physical and psychological disorders. Also Mingyue, Jian'an, Xia, and Zheng'en (2011) and Zhang, Reinhardt, Gosney, and Li (2013) found that comprehensive rehabilitation, including therapeutic interventions, training and education, and social rehabilitation improved clinical results.

To summarize, the fact that transport is developing dynamically and the numbers of road traffic accident casualties are growing, PTSD may pose a challenge that health care professionals may have to face increasingly often. It is therefore crucial that all members of the therapeutic team are able to identify PTSD symptoms, and to determine its potential impact on the health aspect they deal with, and know how to prove the victims with adequate and effective support.

Limitations of the study. Our study is an attempt at understanding the multifaceted and so far unexplored area of surgically treated hip acetabular fractures. This means that the study has certain limitations. The awareness of these limitations may help improve the future studies planned in this area.

The study results leave the question of the cause and effect of the relationship unanswered. Both interpretations are plausible: the one which suggests that traumatized patients have weaker motivation for therapy, and the one that suggests that limitations to mobility and anxiety about recovering one's health worsen the trauma. It is also possible that the explanatory factor is the severity of the accident - it may place life at risk, impact the development of PTSD, and the severity of the physical injury. The study on trauma, however, cannot have the characteristics of an experiment - therefore the explanations we use have to remain theoretical.

In our study, we did not consider all potential factors determining the risk of PTSD in patients. According to Lee, Choi, Yoon, and Lee (2015) lower extremity fracture, multiple extremity fractures, and higher pain scores were significantly related to the occurrence of PTSD. Vranceanu et al. (2014) concluded that psychological factors (catastrophic thinking, in particular) are strongly associated with pain intensity and disability in patients recovering from musculoskeletal trauma. Further research is needed to determine which patient's psychological characteristics, trauma and surgery factors affect the severity of PTSD symptoms.

Another limitation is the size of the study population. The reason was the limited availability of such patients (and limited number of specialist centers), as well as restrictive inclusion criteria for the study. These criteria had to be introduced in order to exclude the influence of other factors on studied parameters. In future it would be advisable to involve a larger population of patients in the study, so that the obtained results could be extrapolated on greater populations. Still, the relationships we observed may help in defining the future studies' focus more precisely.

To summarize we are aware of main limitations that were: relatively small sample size - further studies might include larger population suffering form also other fractures, type of analysis - in future screening together with psychological consultation could be performed directly after surgery and at follow - up to monitor persistent symptoms, use of other psychological questionnaires could be reasonable. We highlight the practical implications of the study: usage of questionnaire to initially search for objective early symptoms of PTSD and 
to monitor its developing from both a clinical and a scientific point of view.

The value of the study. An advantage of this study is its innovative character. The PTSD-C questionnaire can be conducted by professional who are not psychologists, yet the analysis of obtained results was carried out in cooperation with a psychologist who has many years of professional expertise. This allowed us to study the issue in greater depth.

Conducting the study in one single center, in which all the surgical reconstructions of the acetabulum were carried out by the same qualified medical team, with the use of the same health care standards allowed for the homogeneity of the group in respect of the surgical methods applied and the post-surgical treatment that followed. The study protocol was carried out by the same person each time - this minimized the measurement error related to the person of the researcher.

\section{Conclusions}

1. Patients with surgical reconstruction of the acetabulum have lowered levels of functional ability. The injury and surgery may predispose patients towards developing PTSD.

2. It is advisable to make medical staff who treat accident victims aware of aspects which may be related to disorders of the patient's' psychological health. This finding have important practical implications for prevention and intervention in post- traumatic health problems for practitioners, including surgeons, therapists, counselors, and policymakers,.

Authors Contribution Aleksandra Truszczyńska-Baszak: conception and design; analysis and interpretation of data; drafting the article or revising it critically for important intellectual content.

Monika Guszkowska: analysis or interpretation of data; revising article critically for important intellectual content.

Emilia Dadura: collection, analysis or interpretation of data; drafting the article.

Adam Tarnowski: conception and design; analysis or interpretation of data; drafting the article and revising it critically for important intellectual content.

Funding This work was supported by the statutory research programme No. DS. 213 Jozef Pilsudski University of Physical Education, Poland.

Data Availability Data available from corresponding author on request.

Code Availability Not applicable.

\section{Declarations}

Human Animal Rights All procedures performed in studies involving human participants were in accordance with the ethical standards of the institutional research committee and with the 1964 Helsinki Declaration and its later amendments or comparable ethical standards.

Ethical review committee statement of Senate Commission of Ethics of Scientific Research nr SKE 01-21/2014 was obtained.

Informed Consent Informed consent was obtained from all individual adult participants included in the study.

Consent for Publication The authors declare that they agreed on publication.

Conflict of Interest The authors declare that they have no conflict of interest.

Open Access This article is licensed under a Creative Commons Attribution 4.0 International License, which permits use, sharing, adaptation, distribution and reproduction in any medium or format, as long as you give appropriate credit to the original author(s) and the source, provide a link to the Creative Commons licence, and indicate if changes were made. The images or other third party material in this article are included in the article's Creative Commons licence, unless indicated otherwise in a credit line to the material. If material is not included in the article's Creative Commons licence and your intended use is not permitted by statutory regulation or exceeds the permitted use, you will need to obtain permission directly from the copyright holder. To view a copy of this licence, visit http://creativecommons.org/licenses/by/4.0/.

\section{References}

Aaron, D. L., Fadale, P. D., Harrington, C. J., \& Born, C. T. (2011). Posttraumatic stress disorder in civilian orthopaedics. Journal of the American Academy of Orthopaedic Surgeons, 19, 245-250. https://doi.org/10.5435/00124635-201105000-00001.

Aaseth, J., Roer, G. E., Lien, L., \& Bjørklund, G. (2019). Is there a relationship between PTSD and complicated obesity? A review of the literature. Biomedicine \& Pharmacotherapy, 117, 108834. https://doi.org/10.1016/j.biopha.2019.108834.

Alvarez, J., Pavao, J., Baumrind, N., \& Kimerling, R. (2007). The relationship between child abuse and adult obesity among California women. American Journal of Preventive Medicine, 33, 28-33. https://doi.org/10.1016/j.amepre.2007.02.036.

American Psychiatric Association. (2013). Diagnostic and statistical manual of mental disorders (5th ed.). Washington.

Aprato, A., Joeris, A., Tosto, F., Kalampoki, V., Stucchi, A., \& Masse, A. (2016). Direct and indirect costs of surgically treated pelvic fractures. Archives of Orthopaedic and Trauma Surgery, 136, 325330. https://doi.org/10.1007/s00402-015-2373-9.

Berntsen, D., Johannessen, K. B., Thomsen, Y. D., Bertelsen, M., Hoyle, R., \& Rubin, D. (2012). Peace and war: Trajectories of posttraumatic stress disorder symptoms before, during and after military deployment in Afghanistan. Psychological Science, 23, 1557-1565. https:// doi.org/10.1177/0956797612457389.

Clapp, J. D., Masci, J., Bennett, S. A., \& Beck, J. G. (2010). Physical and psychosocial functioning following motor vehicle trauma: Relationships with chronic pain, posttraumatic stress, and medication use. European Journal of Pain, 14, 418-425. https://doi.org/10. 1016/j.ejpain.2009.06.007.

Cowden Hindash, A. H., Lujan, C., Howard, M., O'Donovan, A., Richards, A., Neylan, T. C., \& Inslicht, S. S. (2019). Gender differences in threat biases: Trauma type matters in posttraumatic stress disorder. Journal of Traumatic Stress, 32, 701-711. https://doi.org/ $10.1002 /$ jts.22439. 
Culemann, U., Tosounidis, G., \& Pohlemann, T. (2009). Aktuelle Behandlungsstrategien nach Azetabulumfrakturen. Orthopädie und Unfallchirurgie up2date, 4(04), 229-248.

Cremeans-Smith, J. K., Contrera, K., Speering, L., Miller, E. T., Pfefferle, K., Greene, K., \& Delahanty, D. L. (2015). Using established predictors of post-traumatic stress to explain variations in recovery outcomes among orthopedic patients. Journal of Health Psychology, 20, 1296-1304. https://doi.org/10.1177/ 1359105313511135.

Dedert, E. A., Becker, M. E., Feummeler, B. F., Braxton, L. E., Calhoun, P. S., \& Beckham, J. C. (2010). Childhood traumatic stress and obesity in women: The intervening effects of PTSD and MDD. Journal of Traumatic Stress, 23, 785-793. https://doi.org/10.1002/ jts. 20584 .

Dente, C. J., Feliciano, D. V., Rozycki, G. S., Wyrzykowski, A. D., Nicholas, J. M., Salomone, J. P., \& Ingram, W. L. (2005). The outcome of open pelvic fractures in the modern era. American Journal of Surgery, 190, 830-835. https://doi.org/10.1016/j. amjsurg.2005.05.050.

Fekadu, W., Mekonen, T., Belete, H., Belete, A., \& Yohannes, K. (2019). Incidence of post-traumatic stress disorder after road traffic accident. Frontiers in Psychiatry, 10, 519. https://doi.org/10.3389/fpsyt.2019. 00519.

Giannoudis, P. V., Nikolau, V. S., Kheir, E., Mehta, S., Stengel, D., \& Roberts, C. S. (2009). Factors determining quality of life and level of sporting activity after internal fixation of an isolated acetabular fracture. Journal of Bone and Joint Surgery, 91, 1354-1359. https://doi. org/10.1302/0301-620X.91B10.22572.

Grotz, M. R., Allami, M. K., Harwood, P., Pape, H. C., Krettek, C., \& Giannoudis, P. V. (2005). Open pelvic fractures: Epidemiology, current concepts of management and outcome. Injury, 36, 1-13. https://doi.org/10.1016/j.injury.2004.05.029.

Harvey, A. G., \& Bryant, R. A. (1998). The relationship between acute stress disorder and posttraumatic stress disorder: A prospective evaluation of motor vehicle accident survivors. Journal of Consulting and Clinical Psychology, 66, 507-512. https://doi.org/10.1037// 0022-006x.66.3.507.

Herrera-Escobar, J.P., Apoj, M., Weed, C., Harlow, A.F., Al Rafai, S.S., Lilley E, ... Haider, A. H. (2018). Association of pain after trauma with long-term functional and mental health outcomes. The Journal of Trauma and Acute Care Surgery, 85, 773-779. https://doi.org/10. 1097/TA.0000000000002017.

Iteke, O., Bakare, M. O., Agomoh, A. O., Uwakwe, R., \& Onwukwe, J. U. (2011). Road traffic accidents and posttraumatic stress disorder in an orthopedic setting in South-Eastern Nigeria: a controlled study. Scandinavian Journal of Trauma, Resuscitation and Emergency Medicine, 19, 39. https://doi.org/10.1186/1757-7241-19-39.

Jeavons, S., \& Greenwood, K. M. (2000). Patterns of posttraumatic stress over 12 months following rural road accidents. Australasian Psychiatry, 8, 137-141. https://doi.org/10.1023/A:1007797904536.

Jenewein, J., Wittmann, L., Moergeli, H., Creutzig, J., \& Schnyder, U. (2009). Mutual influence of posttraumatic stress disorder symptoms and chronic pain among injured accident survivors: A longitudinal study. Journal of Traumatic Stress, 22, 540-548. https://doi.org/10. $1002 /$ jts. 20453.

Jiang, T., Veres, K., Körmendiné Farkas, D., Lash, T. L., Toft Sørensen, H., \& Gradus, J. L. (2018). Post-traumatic stress disorder and incident fractures in the Danish population. Osteoporosis International, 29, 2487-2493. https://doi.org/10.1007/s00198-018-4644-0.

Johannessen, K. B., \& Berntsen, D. (2013). Losing the symptoms: Weight loss and decrease in posttraumatic stress disorder symptoms. Journal of Clinical Psychology, 69(6), 655-660. https://doi.org/10. $1002 /$ jclp. 21962.

Johnson, L., Igoe, E., Kleftouris, G., Papachristos, IV., Papakostidis, C., \& Giannoudis, P.V. (2019). Physical health and psychological outcomes in adult patients with long-bone fracture non-unions:
Evidence today. Journal of Clinical Medicine, 8. https://doi.org/ $10.3390 / \mathrm{jcm} 8111998$.

Kenardy, J., \& Dunne, R. (2011). Traumatic injury and traumatic stress. Spine, 36, S233-S237.

Kirmit, L., Karatosun, V., Unver, B., Bakirhan, S., Sen, A., \& Gocen, Z. (2005). The reliability of hip scoring systems for total hip arthroplasty candidates: Assessment by physical therapists. Clinical Rehabilitation, 19, 659-661. https://doi.org/10.1191/ 0269215505cr869oa.

Kornfield, S. L., Lenze, E. J., \& Rawson, K. S. (2017). Predictors of posttraumatic stress symptoms and association with fear of falling after hip fracture. Journal of the American Geriatrics Society, 65, 1251-1257. https://doi.org/10.1111/jgs.14771.

Lang, P., Schnegelberger, A., Riesner, H. J., Stuby, F., Friemert, B., \& Palm, H. G. (2016). Einfluss von operativ versorgten Beckenringund Azetabulumfrakturen auf die posturale Kontrolle. Zeitschrift für Orthopädie und Unfallchirurgie, 154, 174-180. https://doi.org/10. 1055/s-0041-110811.

Lee, C. H., Choi, C. H., Yoon, S. Y., \& Lee, J. K. (2015). Posttraumatic stress disorder associated with orthopaedic trauma: A study in patients with extremity fractures. Journal of Orthopaedic Trauma, 29, e198-e202. https://doi.org/10.1097/BOT.0000000000000255.

Merle D'Aubigne, R., \& Postel, M. (2009). The classic: Functional results of hip arthroplasty with acrylic prosthesis. Clinical Orthopaedics and Related Research, 467, 7-27. https://doi.org/10. 1007/s11999-008-0572-1.

Mingyue, X., Jian'an, L., Xia, Z., \& Zheng'en, Z. (2011). Factors affecting functional outcome of Sichuan-earthquake survivors with tibial shaft fractures: A follow-up study. Journal of Rehabilitation Medicine, 43, 515-520. https://doi.org/10.2340/16501977-0813.

Moliere, S., Dosch, J. C., \& Bierry, G. (2016). Pelvic, acetabular and hip fractures: What the surgeon should expect from the radiologist. Diagnostic and Interventional Imaging, 97, 709-723. https://doi. org/10.1016/j.diii.2016.02.010.

Muscatelli, S., Spurr, H., O Hara, N. N., O Hara, L. M., Sprague, S. A., \& Slobogean, G. P. (2017). Prevalence of depression and posttraumatic stress disorder after acute orthopaedic trauma: A systematic review and meta-analysis. Journal of Orthopaedic Trauma, 31, 4755. https://doi.org/10.1097/BOT.0000000000000664.

Ni, J., Reinhardt, J. D., Zhang, X., Xiao, M., Li, L., Jin, H., Zeng, X., \& $\mathrm{Li}, \mathrm{J}$. (2013). Dysfunction and post-traumatic stress disorder in fracture victims 50 months after the Sichuan earthquake. PLoS One, 29, e77535. https://doi.org/10.1371/journal.pone.0077535 eCollection 2013.

Norman, S. B., Stein, M. B., Dimsdale, J. E., \& Hoyt, D. B. (2008). Pain in the aftermath of trauma is a risk factor for post-traumatic stress disorder. Psychological Medicine, 38, 533-542. https://doi.org/10. 1017/S0033291707001389.

Page, G. M., Kleiman, V., Asmundson, G. J. G., \& Katz, J. (2009). Structure of posttraumatic stress disorder symptoms in pain and pain-free patients scheduled for major surgery. The Journal of Pain, 10, 984-991. https://doi.org/10.1016/j.jpain.2009.03.011.

Pineles, S. L., Arditte Hall, K. A., \& Rasmusson, A. M. (2017). Gender and PTSD: Different pathways to a similar phenotype. Current Opinion in Psychology, 14, 44-48. https://doi.org/10.1016/j. copsyc.2016.11.002.

Soderman, P., \& Malchau H. (2001). Is the Harris hip score system useful to study the outcome of total hip replacement? Clinical Orthopaedics and Related Research, 189-197. https://doi.org/10.1097/00003086200103000-00022.

Ugino, F. K., Righetti, C. M., Alves, D. P. L., Guimarães, R. P., Honda, E. K., \& Ono, N. K. (2012). Evaluation of the reliability of the modified Merle d'Aubigné and Postel method. Acta Ortopédica Brasileira, 20(4), 213-217. https://doi.org/10.1590/S141378522012000400004 . 
Vranceanu, A. M., Bachoura, A., Weening, A., Vrahas, M., Smith, R. M., \& Ring, D. (2014). Psychological factors predict disability and pain intensity after skeletal trauma. Journal of Bone and Joint Surgery (American), 96, e20. https://doi.org/10.2106/JBJS.L.00479.

Walter, S., Leissner, N., Jerg-Bretzke, L., Hrabal, V., \& Traue, H. C. (2010). Pain and emotional processing in psychological trauma. Psychiatria Danubina, 22, 465-470.

Warren, A. M., Jones, A. L., Bennett, M., Solis, J. K., Reynolds, M., Rainey, E. E., Viere, G., \& Foreman, M. L. (2016). Prospective evaluation of posttraumatic stress disorder in injured patients with and without orthopaedic injury. Journal of Orthopaedic Trauma, 30, e305-e311. https://doi.org/10.1097/BOT.0000000000000623.

Wiseman, T., Foster, K., \& Curtis, K. (2013). Mental health following traumatic physical injury: An integrative literature review. Injury, 44, 1383-1390. https://doi.org/10.1016/j.injury.2012.02.015.

Zatzick, D., Rivara, F. P., Nathens, A. B., Jurkovich, G. J., Wang, J., Fan, M. Y., Russo, J., Salkever, D. S., \& Mackenzie, E. J. (2007). A nationwide U.S. student of post-traumatic stress after hospitalization for physical injury. Psychological Medicine, 37, 1469-1480. https:// doi.org/10.1017/S0033291707000943.
Zatzick, D. F., Kang, S., Muller, H., Russo, J. E., Rivara, F. P., Katon, W., Jurkovich, G. J., \& Roy-Byrne, P. (2002). Predicting posttraumatic distress in hospitalized trauma survivors with acute injuries. American Journal of Psychiatry, 159, 941-946. https://doi.org/10. 1176/appi.ajp.159.6.941.

Zawadzki, B., Strelau, J., Bieniek, A., Sobolewski, A., \& Oniszczenko, W. (2002). Kwestionariusz PTSD-wersja kliniczna (PTSD-K): Konstrukcja narzędzia do diagnozy zespołu stresu pourazowego. [PTSD questionnaire-clinical version (PTSD-C): Design of a tool for the diagnosis of post-traumatic stress disorder ]. Przeglad Psychologiczny, 45(3), 289-315.

Zhang, X., Reinhardt, J. D., Gosney, J. E., \& Li, J. (2013). The NHV rehabilitation services program improves long-term physical functioning in survivors of the 2008 Sichuan earthquake: a longitudinal quasi experiment. PLoS One, 8, e53995. https://doi.org/10.1371/ journal.pone.0053995.

Publisher's Note Springer Nature remains neutral with regard to jurisdictional claims in published maps and institutional affiliations. 